BMJ Paediatrics Open

\section{Cross-sectional study of paediatric case mix presenting to an emergency centre in Cape Town, South Africa, during COVID-19}

To cite: Akuaake LM, Hendrikse C, Spittal G, et al. Cross-sectional study of paediatric case mix presenting to an emergency centre in Cape Town, South Africa, during COVID-19. BMJ Paediatrics Open 2020;4:e000801. doi:10.1136/

bmjpo-2020-000801

- Additional material is published online only. To view, please visit the journal online (http://dx.doi.org/10.1136/ bmjpo-2020-000801)

Received 14 July 2020 Revised 8 September 2020 Accepted 9 September 2020

\section{Check for updates}

C) Author(s) (or their employer(s)) 2020. Re-use permitted under CC BY-NC. No commercial re-use. See rights and permissions. Published by BMJ.

${ }^{1}$ Division of Emergency Medicine, Faculty of Medicine and Health Sciences, Stellenbosch University, Cape Town, South Africa 2Division of Emergency Medicine, University of Cape Town, Cape Town, Western Cape, South Africa

${ }^{3}$ Emergency Centre, Mitchells Plain Hospital and Heideveld Hospital, Cape Town, South Africa

${ }^{4}$ Paediatric Department, Mitchells Plain Hospital, Cape Town, South Africa

Correspondence to Dr Daniël Jacobus van Hoving; nvhoving@sun.ac.za

\section{ABSTRACT}

Objective To describe and compare the effect of level 5 lockdown measures on the workload and case mix of paediatric patients presenting to a district-level emergency centre in Cape Town, South Africa.

Methods Paediatric patients ( $<13$ years) presenting to Mitchells Plain Hospital were included. The level 5 lockdown period (27 March 2020-30 April 2020) was compared with similar 5-week periods immediately before (21 February 2020-26 March 2020) and after the lockdown (1 May 2020-4 June 2020), and to similar time periods during 2018 and 2019. Patient demographics, characteristics, International Statistical Classification of Diseases and Related Health Problems, 10th Revision (ICD-10) diagnosis, disposition and process times were collected from an electronic patient tracking and registration database. The $\chi^{2}$ test and the independent samples median test were used for comparisons.

Results Emergency centre visits during the lockdown period $(n=592)$ decreased by $58 \%$ compared with $2019(n=1413)$ and by $56 \%$ compared with the 2020 prelockdown period $(n=1342)$. The proportion of under 1 year olds increased by $10.4 \%(p<0.001)$, with a $7.4 \%$ increase in self-referrals $(p<0.001)$ and a $6.9 \%$ reduction in referrals from clinics $(p<0.001)$. Proportionally more children were referred to inpatient disciplines $(5.6 \%$, $p=0.001)$ and to a higher level of care $(3.9 \%, p=0.004)$. Significant reductions occurred in respiratory diseases (66.9\%, $\mathrm{p}<0.001)$, injuries $(36.1 \%, \mathrm{p}<0.001)$ and infectious diseases $(34.1 \%, p<0.001)$. All process times were significantly different between the various study periods.

Conclusion Significantly less children presented to the emergency centre since the implementation of the COVID-19 lockdown, with marked reductions in respiratory and infectious-related diseases and in injuries.

\section{INTRODUCTION}

Paediatric emergency care decreases childhood morbidity and mortality, but an epidemic has the potential to disrupt access to care and essential child health services. ${ }^{1-3}$

COVID-19 was declared a global pandemic by the WHO on 11 March 2020 and is caused by SARS-CoV-2. ${ }^{4}$ The pandemic resulted

\section{What is known about the subject?}

The volume of children attending emergency centres varied during previous epidemics.

- Paediatric emergency centre attendances decreased during COVID-19.

\section{What this study adds?}

Significantly less children presented to the emergency centre since the implementation of national COVID-19 level 5 lockdown.

- A greater proportion but smaller numbers of younger and sicker children attended the emergency centre during the COVID-19 lockdown.

- Marked reductions occurred in respiratory diseases, infectious-related diseases and in injuries.

- The proportion of infectious diseases increased in patients $<1$ year, while injuries increased in older children.

in most countries implementing social distancing measures to curb the spread of the disease. The South African government implemented a national lockdown on 27 March 2020, consisting of five levels. ${ }^{5}$ Level 5 is the most restrictive with only essential services permitted to operate and strict limitations on public transport services with regards to capacity and operating times. The sale of alcohol and tobacco is prohibited as well as any form of exercise in public spaces. Lower levels are a stepwise easing of the restrictions imposed on level 5 in varying degrees to attempt to limit community transmission and resurgence of the virus, while allowing for economic recovery. Level 1 allows for near normal activity to resume but with the recommended public health guidelines to be followed at all times, including wearing a facemask, maintaining social distancing of at least $2 \mathrm{~m}$ and frequently washing or sanitising 
hands. The South African lockdown started at level 5, which lasted 5 weeks (27 March-30 April 2020) and was followed by level 4 (1 May-31 May 2020). Level 3 restrictions were implemented on 1 June 2020 and was still in place at the time of data collection.

The implemented lockdown measures under level 5 resulted in all non-urgent healthcare appointments being cancelled, including the de-escalation of services at community healthcare centres and the rescheduling of elective surgeries and outpatient department visits at hospital level. An upsurge in patients visiting the emergency centre was anticipated as most other healthcare services were de-escalated. Furthermore, the pandemic and subsequent lockdown periods coincided with autumn and the beginning of winter where an increase in respiratory-related cases are typically experienced, especially in the paediatric population. However, the effect of the closing of early childhood development centres and schools, as well as most parents forced to work from home, are unknown but could also change the number and type of presentations to the emergency centre.

Previous studies presented conflicting results of healthcare utilisation during an epidemic. An increase in paediatric patients presenting to emergency centres was seen during the swine influenza (H1N1pdm09 virus) pandemic in 2009. ${ }^{6-8}$ However, paediatric-related presentations decreased by up to $40 \%$ during the 2015 Middle East respiratory syndrome (MERS) epidemic in Korea. ${ }^{9}{ }^{10}$ A more pronounced decrease $(80 \%)$ was witnessed during the 2003 severe acute respiratory syndrome (SARS) epidemic in Taiwan. ${ }^{11}$ A decline in trauma cases presenting to emergency centres across South Africa has already been noticed, ${ }^{12}$ but the effect of the national lockdown on paediatric presentations remains unclear. The aim of the study was to describe and compare the effect of the level 5 national COVID-19 lockdown measures on the workload and case mix of paediatric patients presenting to a district-level emergency centre in Cape Town, South Africa.

\section{METHODS}

\section{Study design}

A descriptive analysis was conducted on existing data. Data were extracted from an existing database that collects routine data prospectively (in real time).

\section{Study setting}

Mitchells Plain Hospital is a 365-bed hospital providing district hospital health services to the surrounding community. It serves a low-income to middle-income health district of approximately 600000 people. ${ }^{13}{ }^{14}$ The health district has many social challenges, including gangsterism, crime and drug abuse. Interpersonal violence and other injuries are particularly prevalent during weekends. ${ }^{15}$ Mitchells Plain Hospital is situated on the outskirts of Cape Town and has an emergency centre that manages around 4100 patients per month; 950 being children under the age of 13 years. A quarter of the children are deemed very urgent or emergent at presentation (orange or red according to the South African Triage Scale (SATS) ), ${ }^{16}$ and an average of 135 are admitted to the inpatient paediatric service. Monthly paediatric presentations increase to around 1200 during the annual respiratory surge season (March-June), of which about 190 are admitted. Normally, the paediatric department assists with providing staff for the emergency centre, and non-specialist physicians from the paediatric department have been the treating clinician for around $40 \%$ of acute paediatric presentations. Since the lockdown measures

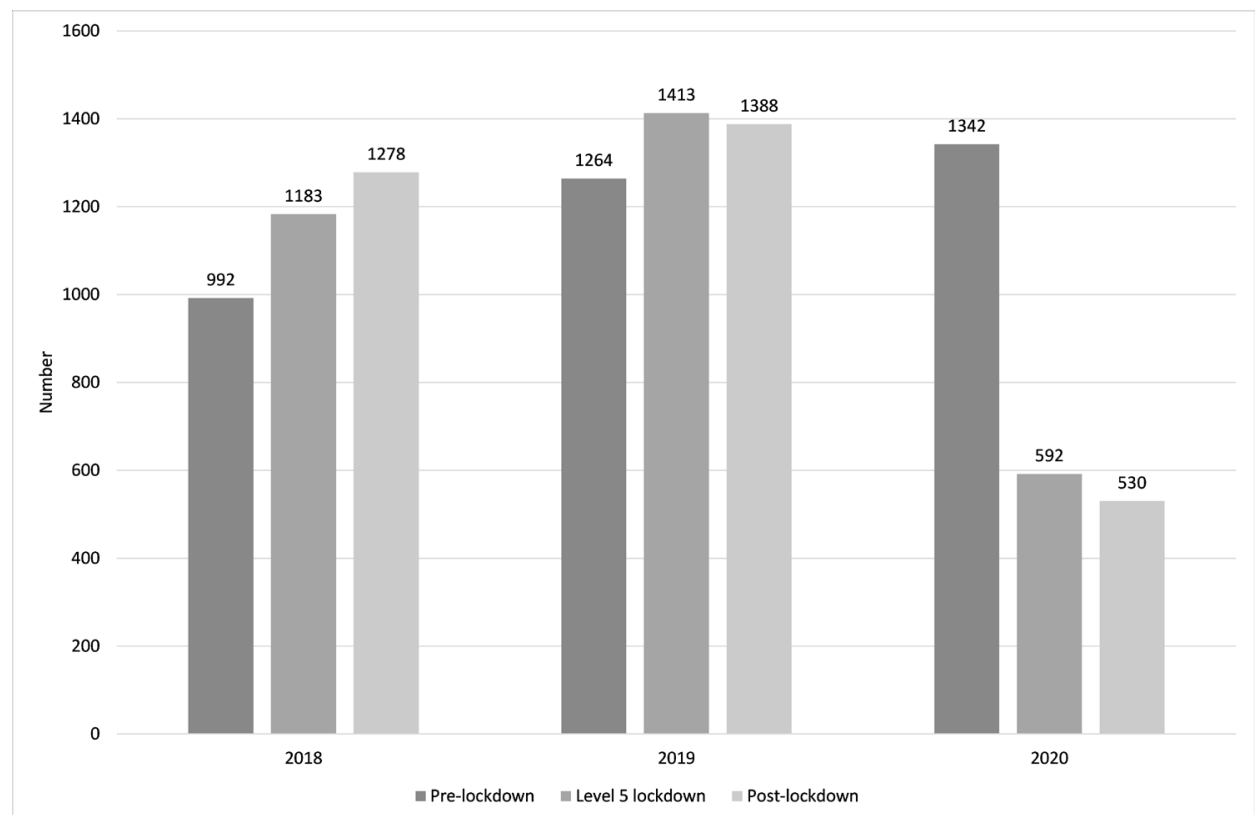

Figure 1 Number of paediatric emergency centre visits over a 5-week period before, during and after the COVID-19 level 5 lockdown. 
Table 1 Demographics and characteristics of paediatric patients presenting to the emergency centre during the level 5 COVID-19 lockdown period and corresponding 5-week periods immediately before and after the lockdown

\begin{tabular}{|c|c|c|c|}
\hline $\begin{array}{l}\text { Variables } \\
\mathrm{n}(\%)\end{array}$ & $\begin{array}{l}21 \text { February-26 March } \\
\text { (prelockdown) }\end{array}$ & $\begin{array}{l}27 \text { March-30 April (level } 5 \\
\text { lockdown) }\end{array}$ & $\begin{array}{l}1 \text { May-4 June } \\
\text { (postlockdown) }\end{array}$ \\
\hline \multicolumn{4}{|l|}{ Age (year) } \\
\hline$<1$ & $243(18.1)$ & $169(28.5)^{\star}$ & $116(21.9) \dagger$ \\
\hline $1-5$ & $787(58.6)$ & $314(53)^{\star}$ & $279(52.6)$ \\
\hline$>5$ & $312(23.2)$ & $109(18.4)^{\star}$ & $135(25.5) \dagger$ \\
\hline \multicolumn{4}{|l|}{ Gender } \\
\hline Female & $565(42.1)$ & $267(45.1)$ & $251(47.4)$ \\
\hline Male & 777 (57.9) & $325(54.9)$ & 279 (52.6) \\
\hline \multicolumn{4}{|l|}{ Transport method } \\
\hline Self & $1115(83.1)$ & $489(82.6)$ & $476(89.8) \dagger$ \\
\hline Ambulance & $145(10.8)$ & $69(11.7)$ & $52(9.8)$ \\
\hline Police or fire service & $0(0)$ & $0(0)$ & $0(0)$ \\
\hline Unknown & $82(6.1)$ & $34(5.7)$ & $2(0.4) \dagger$ \\
\hline \multicolumn{4}{|l|}{ Arrival from } \\
\hline Scene/home & $1000(74.5)$ & $485(81.9)^{*} \ddagger$ & $457(86.2) \S$ \\
\hline Other healthcare facility & $260(19.4)$ & $74(12.5)^{\star} \ddagger$ & $52(9.8) \S$ \\
\hline General practitioner & $81(6)$ & $33(5.6)$ & $21(4) \S$ \\
\hline Unknown & $1(0.1)$ & $0(0)$ & $0(0)$ \\
\hline \multicolumn{4}{|l|}{ Triage category } \\
\hline Non-urgent (green) & $344(25.6)$ & $142(24)$ & $172(32.5)+\S$ \\
\hline Urgent (yellow) & $663(49.4)$ & $300(50.7)$ & $256(48.3)$ \\
\hline Very urgent (orange) & 267 (19.9) & $115(19.4)$ & $78(14.7) \dagger \S$ \\
\hline Emergency (red) & $30(2.2)$ & $25(4.2)^{\star}$ & $17(3.2)$ \\
\hline Unknown & $38(2.8)$ & $10(1.7)$ & $7(1.3)$ \\
\hline \multicolumn{4}{|l|}{ Disposition } \\
\hline Death & $4(0.3)$ & $4(0.7)$ & $0(0)$ \\
\hline Referred to in-hospital disciplines & 163 (12.1)ף & $105(17.7)^{\star}$ & $91(17.2) \S$ \\
\hline Discharged & $871(64.9)$ & $351(59.3)^{*} \ddagger$ & $346(65.3)+\S$ \\
\hline Absconded & 160 (11.9)ף & $33(5.6)^{\star}$ & $13(2.5) \dagger \S$ \\
\hline Transferred to higher level facility & $92(6.9)$ & $64(10.8)^{\star} \ddagger$ & $65(12.3) \S$ \\
\hline Refer to other & $52(3.9) \emptyset$ & $35(5.9)$ & $15(2.8) \dagger$ \\
\hline
\end{tabular}

*Statistically significant difference $(p<0.05)$ between prelockdown period 2020 and level 5 lockdown period 2020 (see online supplemental table 2).

†Statistically significant difference $(p<0.05)$ between level 5 lockdown period 2020 and postlockdown period 2020 (see online supplemental table 2).

¥Statistically significant difference $(p<0.05)$ between level 5 lockdown period 2019 and 2020 (see online supplemental table 2).

$\S$ Statistically significant difference $(p<0.05)$ between postlockdown period 2019 and 2020 (see online supplemental table 2).

ๆStatistically significant difference $(p<0.05)$ between prelockdown period 2019 and 2020 (see online supplemental table 2).

came into effect, the paediatric department has been responsible for over $90 \%$ of acute paediatric presentations to free up emergency centre staff to assist with the adult workload. This was made possible by closing the paediatric outpatient department and reverting to telephonic consultations that needed less staff.

An electronic patient tracking and registration database (Hospital and Emergency Centre Tracking Information System (HECTIS)) is used to collect routine clinical data for each patient that is managed within the emergency centre.

HECTIS is an official electronic application of the Western Cape Department of Health, which follows the flow of patients in an emergency centre from arrival to discharge or admission. It is used by numerous emergency centres to streamline patient processes and capture data related to process times, triage scores, International Statistical Classification of Diseases and Related Health 


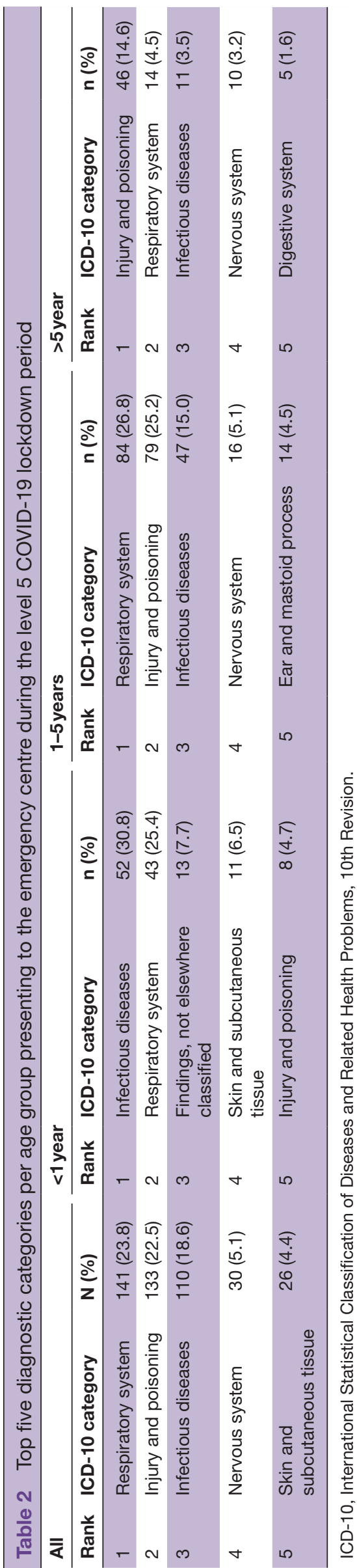

Problems, 10th Revision (ICD-10) diagnoses and dispositions. The database has been built on an Oracle platform and is stored off-site. The database is access controlled, and authorised users are granted access and authorisation according to their specific clinical role. A triage nurse will thus have access to different parts of the database than a clinician in the emergency centre.

\section{Study participants}

Convenience sampling was used to include all patients $<13$ years of age that presented to the emergency centre of Mitchells Plain Hospital over the study periods. Time periods included the level 5 lockdown period (27 March 2020-30 April 2020), a 5-week period immediately before the lockdown (21 February 2020-26 March 2020), a 5 -week period immediately after the lockdown (1 May 2020-4 June 2020) and corresponding periods during 2018 and 2019.

\section{Data collection and management}

Data were exported from the HECTIS database for the various study periods. Variables included age, gender, mode of transport, type of presentation, triage category, ICD-10 diagnosis, process times and disposition. The triage category was determined at arrival to the hospital, and patients were categorised into emergency (red), very urgent (orange), urgent (yellow) and non-urgent (green) as stipulated by the SATS. ${ }^{16}$ Patients' diagnosis was determined from ICD-10 codes documented as the main diagnosis. Disposition refers to where a patient is being discharged from the emergency centre. Patient process times were calculated from electronic timestamps and included time to triage (arrival at emergency centre to time of triage), time to consultation (arrival at emergency centre to time seen by physician), time to disposition (arrival at emergency centre to time when emergency centre disposition was decided) and time in emergency centre (arrival at emergency centre to time when patient left the emergency centre). Process times of patients that absconded were only included to calculate the time to triage (if a triage time was documented) and were excluded from the other process times.

\section{Statistical analysis}

Summary statistics were used to describe all variables. Categorical data are summarised using frequency counts and percentages and are presented as two-way tables or bar charts. Median was used as the measure of central tendency for continuous responses and quartiles as indicators of spread. The relationship between categorical variables was determined with the $\chi^{2}$ test or the Fisher's exact test, and process times were compared with the independent samples median test. A 5\% significance level was used, and data were analysed using SPSS Statistics for Windows, V.26.0.

\section{Patient and public involvement statement}

This research was done without patient involvement. Patients were not invited to comment on the study 
Table 3 Actual and proportional differences of paediatric presentations to the emergency centre during the level 5 lockdown period, compared with similar 5-week periods before and after

\begin{tabular}{|c|c|c|c|c|c|c|}
\hline \multirow[b]{2}{*}{ ICD-10 category } & \multicolumn{3}{|c|}{$\begin{array}{l}21 \text { February-26 March (prelockdown) versus } \\
27 \text { March-30 April (level } 5 \text { lockdown) }\end{array}$} & \multicolumn{3}{|c|}{$\begin{array}{l}27 \text { March-30 April (level } 5 \text { lockdown) } \\
\text { versus } 1 \text { May-4 June (postlockdown) }\end{array}$} \\
\hline & $\begin{array}{l}\text { Actual } \\
\mathrm{n}(\%)\end{array}$ & $\begin{array}{l}\text { Proportional } \\
(\%)\end{array}$ & $P$ value & $\begin{array}{l}\text { Actual } \\
\mathrm{n}(\%)\end{array}$ & Proportional & $P$ value \\
\hline I. Certain infectious and parasitic diseases & $-57(-34.1)$ & 6.2 & $<0.001$ & $-40(-36.4)$ & -5.4 & 0.015 \\
\hline VI. Diseases of the nervous system & $-12(-28.6)$ & 2.0 & 0.050 & $-14(-46.7)$ & -2.1 & 0.097 \\
\hline VIII. Diseases of the ear and mastoid process & $-43(-66.2)$ & -1.1 & 0.287 & $-8(-36.4)$ & -1.1 & 0.316 \\
\hline $\mathrm{XI}$. Diseases of the digestive system & $-17(-60.7)$ & -0.2 & 0.861 & $13(118.2)$ & 2.6 & 0.015 \\
\hline $\begin{array}{l}\text { XII. Diseases of the skin and subcutaneous } \\
\text { tissue }\end{array}$ & $-23(-46.9)$ & 0.7 & 0.445 & $-2(-7.7)$ & 0.1 & 1.000 \\
\hline XIV. Diseases of the genitourinary system & $-26(-65.0)$ & -0.6 & 0.462 & $-2(-14.3)$ & -0.1 & 1.000 \\
\hline $\begin{array}{l}\text { XVIII. Symptoms, signs and abnormal clinical } \\
\text { and laboratory findings, not elsewhere } \\
\text { classified }\end{array}$ & $-64(-71.9)$ & -2.4 & 0.046 & $6(24.0)$ & 1.6 & 0.220 \\
\hline
\end{tabular}

ICD-10, International Statistical Classification of Diseases and Related Health Problems, 10th Revision.

design and were not consulted to develop patient relevant outcomes or interpret the results. Patients were not invited to contribute to the writing or editing of this document for readability or accuracy.

\section{RESULTS}

\section{Overall emergency centre visits}

A total of 39905 emergency centre visits were documented over the study periods, of which 9983 were younger than 13 years of age (a 15\% reduction in all (adult and paediatric) emergency centre visits compared with 2019 was observed, as well as a $35 \%$ reduction over the lockdown period). ${ }^{17}$ One patient was excluded as the visit only pertained to special investigations; 9982 were thus analysed. There were 2464 paediatric emergency centre visits during the 2020 time periods, 1601 less than in 2019 $(\mathrm{n}=4065)$ and 989 less than in $2018(\mathrm{n}=3453)$. There was a $6.2 \%(n=78)$ increase in the actual number of patients seen during the 2020 prelockdown period compared with 2019 , followed by a $58.1 \%(n=821)$ reduction for the level 5 lockdown periods and a $61.8 \%(\mathrm{n}=858)$ reduction over the postlockdown periods (figure 1).

\section{Demographics and characteristics}

The demographics and characteristics of patients whom presented during 2020 are presented in table 1 (see online supplemental table 1 for data pertaining to 2018 and 2019). Significant differences during level 5 lockdown compared with the 2020 prelockdown period were seen in patient's age, referral type, triage category and disposition. The proportion of children younger than 1 year increased by $10.4 \%(\mathrm{p}<0.001)$, with a decrease in the $1-5$ year group $(5.6 \%, \mathrm{p}=0.022)$ and in patients over the age of 5 years $(4.8 \%, \mathrm{p}=0.02)$. The proportions in the age category changed as lockdown measures were eased; children over 5 years were the only group showing an increase $(7.1 \%, \mathrm{p}=0.005)$. An increase in the proportion of self-referrals occurred $(7.4 \%, \mathrm{p}<0.001)$, with a subsequent decrease in referrals from primary healthcare clinics $(6.9 \%, \mathrm{p}<0.001)$ and general practitioners $(0.4 \%$, $\mathrm{p}=0.754$ ). Children presenting during the level 5 lockdown periods were also sicker with a $2 \%$ increase in the proportion of emergency (triaged red) cases $(p=0.018)$, although the actual number of patients decreased $(n=5)$. The difference in triage category most likely contributed to the proportional increase of inpatient referrals $(5.6 \%$, $\mathrm{p}=0.001)$, as well as patients referred for higher level of care $(3.9 \%, p=0.004)$. This also resulted in a proportional decrease in patients being discharged directly home from the emergency centre $(5.6 \%, \mathrm{p}=0.019)$.

\section{Diagnostic categories}

The top three diagnostic categories during the level 5 lockdown were related to the respiratory system $(n=141$, $23.8 \%)$, injuries and poisonings $(\mathrm{n}=133,22.5 \%)$ and infectious diseases $(n=110,18.6 \%)$. In the different age groups, infectious diseases were most frequent in the under 1-year group $(\mathrm{n}=52,30.8 \%)$, respiratory-related diseases in the $1-5$ year group $(n=84,26.8 \%)$ and injuryrelated presentations in the over 5-year group $(n=46$, $14.6 \%$ ) (table 2). The top five diagnostic categories per age group and per time period is presented in online supplemental table 3 . The actual number of presentations during the level 5 lockdown decreased in all the diagnostic categories compared with the 2020 prelockdown period (table 3). Significant reductions occurred in respiratory diseases $(\mathrm{n}=285,66.9 \%, \mathrm{p}<0.001)$, injuries $(\mathrm{n}=75,36.1 \%, \mathrm{p}<0.001)$ and infectious and parasitic diseases $(\mathrm{n}=57,34.1 \%, \mathrm{p}<0.001)$. Proportionally, diseases of the respiratory system decreased by $7.9 \%$, 


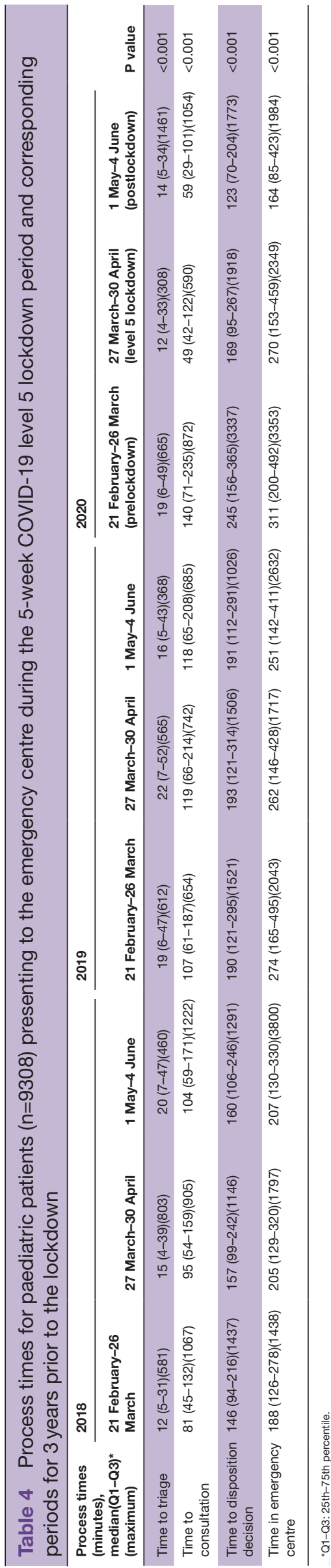

infectious-related diseases increased by $6.2 \%$ and injuries increased by $7.0 \%$ (table 3) (see online supplemental table 4 for comparisons of 2020 vs 2019 and 2020 vs 2018). The diagnostic categories for all the time periods are presented in online supplemental table 5. In admitted patients, actual infectious-related diseases decreased by $40 \%(\mathrm{n}=24)$ and diseases of the respiratory system by $63 \%$ $(\mathrm{n}=67)$ during the lockdown period compared with 2019. A $28 \%(n=14)$ reduction was seen in actual infectiousrelated and respiratory-related diseases comparing the 2020 lockdown periods (see online supplemental table 6 for the diagnostic categories of admitted patients). In patients transferred to higher level of care, actual infectious-related diseases increased by $91 \% \quad(\mathrm{n}=10)$ and injuries by $33 \%(\mathrm{n}=4)$ during the lockdown period compared with 2019. A $30 \%(n=7)$ reduction was seen in the actual number of injuries and a $5 \%(n=1)$ increase in infectious-related diseases comparing the 2020 lockdown periods (see online supplemental table 7 for the diagnostic categories of transferred patients).

\section{Process times}

All process times were significantly different between the various study periods (table 4). Comparing median times between the level 5 lockdown period and the 2020 prelockdown period, time to triage decreased by $7 \mathrm{~min}$ $(\mathrm{p}<0.001)$, time to consultation by $91 \mathrm{~min}(\mathrm{p}<0.001)$, time to deciding disposition by $76 \mathrm{~min}(\mathrm{p}<0.001)$ and length of stay within the emergency centre by $41 \mathrm{~min}(\mathrm{p}=0.003)$.

\section{DISCUSSION}

The volume of children visiting the emergency centre during and after the level 5 lockdown period was significantly lower than similar previous time periods. Significant reductions in the number of presentations were seen in respiratory diseases, infectious diseases and injuries (table 3). A reduction in the proportion of diseases related to the respiratory system occurred in all age groups, while infectious diseases increased in younger patients (<1year) and injuries increased in children older than 1 year.

The overall reduction in paediatric emergency centre visits is similar to experiences from the SARS and MERS pandemics, as people tend to avoid or delay attending hospitals due to the fear of contracting the communicable disease. ${ }^{9-11}$ Anecdotal evidence do suggest that attendance to the primary healthcare services also decreased. This is of concern and child health needs to be monitored closely over the coming 12 months. The likely reduction in immunisations, specifically measles, could result in outbreaks of non-COVID-19 communicable diseases causing more morbidity and mortality. ${ }^{3}$ The impact of this would be substantially worse in impoverished communities.

The reduction in respiratory and infectious-related diseases were substantial contributors to the overall reduction in emergency centre attendance, although the 
proportion of children with infectious diseases increased. These reductions are most likely multifactorial, and one important consideration could be the closing of early childhood development centres. It has been well documented that children attending crèches have a higher incidence of infectious diseases, including respiratory tract infections. ${ }^{18} 19$ About three quarters of paediatric emergency centre attendees at Mitchells Plain Hospital are children under the age of 5 years, of whom a large proportion will normally be in formal or informal crèches while their parents work. The lockdown measures forced most parents to stay at home, thereby further reducing children's exposure to infections (COVID-19 and other) as trips to shops or work were limited.

Children presenting with injuries and poisoning decreased by a third during the level 5 lockdown period, but increased proportionally by $7 \%$ (table 3 ). This was not expected and could be from children bypassing the community healthcare centres; thus, children with minor injuries also presented to the hospital. However, the home is one of the most dangerous places for children. It is estimated that around $90 \%$ of unintentional injuries in young children occur in or around their home when they are supposedly being supervised by a caregiver. ${ }^{20}$ Injury risk could also have increased if children became bored at home, while parents were most likely frustrated in the constant supervision of the children. Furthermore, anecdotal evidence suggest that the number of child abuse cases did not decrease during the lockdown periods and remain on a similar trend than before. ${ }^{21}$ Another possible reason is the long-standing problem in South Africa where many children are looking after themselves and other children, with an understandable lack of adequate supervision.

The main strength of the study is the use of a comprehensive database that is completed in real time. Although data are not cross-checked, we expect the data to be adequately reflecting the truth. However, care should be taken to generalise the results of the study to other healthcare facilities as it reflects a single centre in a fairly distinctive setting. Diseases were categorised according to diagnostic codes (ICD-10) assigned by attending physicians. A diagnostic code was not assigned to around 10\% of patients. We also did not validate whether the correct diagnosis were made, neither did we attempt to ensure that the correct diagnostic code were assigned to the diagnosis. This could have resulted in non-systematic error.

\section{CONCLUSION}

Significantly less children presented to the emergency centre since the implementation of the national COVID-19 level 5 lockdown. The closure of early childhood development centres and schools, together with the restriction of movement of children and their caregivers, markedly reduced the infectious and respiratory-related component of paediatric attendees. The burden of injuries in resource-limited societies remains a problem, even during a period of national lockdown. However, the change in paediatric presentations to the emergency centre across all COVID-19 lockdown levels remains unknown and should be investigated in future.

Contributors DJvH and $\mathrm{CH}$ conceived the study. LMA, CH, and KE undertook data collection. LMA and DJvH cleaned the data, and DJvH and CH did the data analyses. LMA drafted the manuscript, and the remaining authors critiqued the paper for important intellectual content. All authors read and approved the final version of the manuscript. LMA is the guarantor.

Funding The authors have not declared a specific grant for this research from any funding agency in the public, commercial or not-for-profit sectors.

Competing interests None declared.

Patient and public involvement Patients and/or the public were not involved in the design, or conduct, or reporting, or dissemination plans of this research.

Patient consent for publication Not required.

Ethics approval The study was approved by the Health Research Ethics Committee of Stellenbosch University (Ref: N20/04/009_COVID-19) and included a waiver of informed consent.

Provenance and peer review Not commissioned; externally peer reviewed.

Data availability statement Deidentified participant data are available from the corresponding author (orcid.org/0000-0002-4300-0372) on reasonable request.

Open access This is an open access article distributed in accordance with the Creative Commons Attribution Non Commercial (CC BY-NC 4.0) license, which permits others to distribute, remix, adapt, build upon this work non-commercially, and license their derivative works on different terms, provided the original work is properly cited, appropriate credit is given, any changes made indicated, and the use is non-commercial. See: http://creativecommons.org/licenses/by-nc/4.0/.

ORCID iD

Daniël Jacobus van Hoving http://orcid.org/0000-0002-4300-0372

\section{REFERENCES}

1 , Yamamoto LG, Krug SE, American Academy of Pediatrics Committee on Pediatric Emergency Medicine. Access to optimal emergency care for children. Pediatrics 2007;119:161-4.

2 Quaglio G, Pizzol D, Bome D, et al. Maintaining maternal and child health services during the Ebola outbreak: experience from Pujehun, Sierra Leone. PLoS Curr 2016;8. doi:10.1371/currents.outbreaks. d67aea257f572201f835772d7f188ba5. [Epub ahead of print: 02 Jun 2016].

3 World Health Organization. Vaccination in acute humanitarian emergencies. Geneva, 2017. https://www.who.int/immunization/ documents/who_ivb_17.03/en/

4 World Health Organization. WHO Timeline - COVID-19, 2020. Available: https://www.who.int/news-room/detail/27-04-2020-whotimeline-covid-19 [Accessed 20 Jun 2020].

5 COVID-19 Risk Adjusted Strategy - SA Corona Virus Online Portal. Available: https://sacoronavirus.co.za/covid-19-risk-adjustedstrategy/ [Accessed 2 Sep 2020]

6 Torres JP, O'Ryan M, Herve B, et al. Impact of the novel influenza A (H1N1) during the 2009 autumn-winter season in a large hospital setting in Santiago, Chile. Clin Infect Dis 2010;50:860-8.

7 Kwan-Gett TS, Baer A, Duchin JS. Spring 2009 H1N1 influenza outbreak in King County, Washington. Disaster Med Public Health Prep 2009;3 Suppl 2:S109-16.

8 Falconer E, Keddy M, Milne WK. Impact of the H1N1 influenza pandemic in two rural emergency departments. Rural Remote Health 2012;12:2063.

9 Lee SY, Khang YH, Lim HK. Impact of the 2015 middle East respiratory syndrome outbreak on emergency care utilization and mortality in South Korea. Yonsei Med J 2019;60:796-803.

10 Paek SH, Kim DK, Lee JH, et al. The impact of middle East respiratory syndrome outbreak on trends in emergency department utilization patterns. J Korean Med Sci 2017;32:1576-80.

11 Huang $\mathrm{H}-\mathrm{H}$, Yen DH-T, Kao W-F, et al. Declining emergency department visits and costs during the severe acute respiratory syndrome (SARS) outbreak. J Formos Med Assoc 2006;105:31-7.

12 Morris D, Rogers M, Kissmer N, et al. Impact of lockdown measures implemented during the Covid-19 pandemic on the burden of trauma presentations to a regional emergency 
department in Kwa-Zulu natal, South Africa. Afr J Emerg Med 2020. doi:10.1016/j.afjem.2020.06.005. [Epub ahead of print: 16 Jun 2020].

13 Statistics South Africa. Mitchells plain. Available: http://www.statssa. gov.za/?page_id=4286\&id=329 [Accessed 17 Apr 2020].

14 Statistics South Africa. Philippi. Available: http://www.statssa.gov. za/?page_id=4286\&id=323 [Accessed 17 Apr 2020].

15 Mitchells Plain Nodal Economic Development Profile Western Cape. Available: https://mitchellsplain.files.wordpress.com/2011/07/ mitchells_20plain_20narrative.pdf

16 South African Triage Group. The South African triage scale (SATS), 2012. Available: https://emssa.org.za/special-interest-groups/thesouth-african-triage-scale-sats/ [Accessed 28 Aug 2019].

17 Hendrikse C, Parak M, van Hoving DJ. A descriptive analysis of the effect of the National COVID-19 lockdown on the workload and case mix of patients presenting to a district-level emergency centre in Cape town, South Africa. S Afr Med J;In Press.

18 Kamper-Jørgensen M, Wohlfahrt J, Simonsen J, et al. Population-Based study of the impact of childcare attendance on hospitalizations for acute respiratory infections. Pediatrics 2006;118:1439-46.

19 Lu N, Samuels ME, Shi L, et al. Child day care risks of common infectious diseases revisited. Child Care Health Dev 2004;30:361-8.

20 World Health Organization. World report on child injury prevention, 2015. Available: https://www.who.int/violence injury prevention/ child/injury/world_report/en/ [Accessed 22 Jun 2020].

21 Cleary K. Fear, sadness and anger: the hidden impact of lockdown on children, 2020. Available: https://www.news24.com/citypress/ News/fear-sadness-and-anger-the-hidden-impact-of-lockdown-onchildren-20200527 [Accessed 23 Jun 2020]. 